\title{
Mechanical Properties of Steel Fiber Reinforced Self-Compacting Concrete
}

\author{
Anıl Niş ${ }^{*}{ }^{\ddagger}$ \\ * Department of Civil Engineering, Faculty of Engineering and Architecture, Istanbul Gelisim University, Istanbul, Turkey \\ (anis@gelisim.edu.tr)
}

† Corresponding Author, Anıl Niş, Department of Civil Engineering, Istanbul Gelisim University, Istanbul, Turkey

Tel: +90 212422 7020, Fax: +90 212422 7401, anis@gelisim.edu.tr

Received: 28.09.2017 Accepted: 12.01.2018

\begin{abstract}
In this study, steel fiber reinforced self - compacting concrete (SFR-SCC) specimens were examined by considering the effects of different parameters on the material performance and to promote the use of fiber materials in building industry. Use of steel fibers in SCC is still limited due to lack of required codes and standards in this field. More research is required to understand the effects of steel fibers on mechanical properties of the concrete. For this purpose, 5 mixes; control and reinforced with 2 different fiber volumes and two different fiber types; were produced. Compressive strength, splitting tensile strength and 3-point notched bending tests were carried out on these specimens for thoroughly evaluating mechanical performance of steel fiber reinforced self-compacting concretes.
\end{abstract}

Keywords Steel fiber reinforced self-compacting concrete, flexural toughness, ductility, three point notched bending, flexural strength.

\section{Introduction}

Self-compacting concrete (SCC) is widely used for construction of civil engineering structures, especially in precast industries, high rise buildings and structures that need congested reinforcement. SCC technology achieved a significant breakthrough in construction industry with the three main advantages which are workability, flowability and passing ability. Thanks to these properties, concrete can be placed to complex shape moulds under its own weight without segregation and/or bleeding. During casting, energy consumption, labour works and construction time are reduced since external vibration is not required. SCC can flow between narrower openings easily; thus, reducing structural element sizes, formwork and material costs.

Plain concrete is a brittle heterogeneous material that is strong in compression conversely weak in tension and flexure. From the light of the structural steel reinforcement contribution to the tensile strength of concrete, steel fiber usage in concrete industry has also been developed recently. Steel fiber reinforced concrete has superior tensile and flexural performance with respect to plain concrete depending on the type and amount of the steel fibers. In addition to this, the role of crack bridging ability and crack width control increases interest in using steel fibers in concrete, especially in the post-cracking phase. Most important contributions of the steel fibers into the concrete are increased toughness (area under the load-deflection curve) especially under flexural loading, increased tensile and shear strength capacity and modified crack formation mechanism. These important properties made fiber reinforced concrete popular in the research.

Steel fiber reinforced concrete (SFRC) has been used in both columns and beams where shear stresses are of critical and steel fibers have been partially used instead of stirrups as shear reinforcement. In high seismic zones, design codes impose the use of transverse reinforcements in order to obtain ductile behaviour and large amounts of transverse reinforcements are required especially in heavier structural elements. However, such congested reinforcements may cause concrete placement problem in narrower structural elements. The use of steel fiber can reduce the amount of transverse reinforcements and can be a solution for the concrete placement. In most situations, high amount of steel fiber reinforcement $(\geq 1 \%)$ is required to obtain better structural performance. However, such amount of steel fiber may also cause workability problem in concrete. A combination of steel fiber reinforced concrete with a self- 
compacting concrete is used and defined as steel fiber reinforced self-compacting concrete (SFR-SCC) in order to obtain high flowability to solve workability and concrete placement problem [1].

SFR-SCC usage has many advantages in concrete industry. SFR-SCC has contributed to noise pollution, construction time and labour cost due to lack of external vibration. In nowadays, electric energy and labour costs become a significant part in the overall cost of the structure. However, SFR-SCC has not been used alone due to lack of structural design codes. It has been used with structural rebar (primary reinforcement) and steel fibers take place as secondary reinforcement in design phase. Structural applications of the SFR-SCC are; slabs and pavements, water tanks, channels, pipes, precast piles, precast walls, and blast resistance structures. SFR-SCC will be used more when steel fibers totally take place of the conventional steel reinforcement with further investigation [2]. In order to promote use of steel fiber, its effects on the mechanical properties of concrete should be further investigated.

\subsection{Factors Influencing Mechanical Properties of SFR-SCC}

Mechanical properties of SFR-SCC are influenced by concrete material components (cement, cementitious material and water amounts) and steel fiber characteristics (steel fiber type, amount and aspect ratio). The effects of the concrete material components to mechanical strength of SRF-SCC has already known in the concrete industry. However, the effect of steel fibers on the mechanical strength of concrete is required further investigation.

\subsubsection{Influence of steel fiber type}

There is a wide range of fiber types, steel fiber, synthetic fiber, glass fiber, natural organic and inorganic fibers; however, steel fibers are the most used fiber types in construction industry. Steel fiber performance is influenced by 3 different properties: (1) the aspect ratio (L/d) of the steel fiber; (2) steel fiber shape (straight, hook-end) and surface deformation; (3) surface treatment. Surface deformation is generally conducted in order to increase the anchorage between matrix and fiber. The used steel fibers have a circular cross section with a diameter changing from $0.2 \mathrm{~mm}$ to $1 \mathrm{~mm}$, with a length varying from $10 \mathrm{~mm}$ to $60 \mathrm{~mm}$ and with an aspect ratio less than 100. For better bond between steel fiber and concrete matrix, steel fibers may be modified by surface and mechanical deformations [3].

For structural applications, straight and hooked-end type steel fibers have been widely used. Plain concrete goes into failure under tensile or flexural loading by formation of a single crack. However, steel fiber reinforced concrete resists additional crack openings and multiple cracks observed before the failure. This is due to two separate mechanisms: (1) when tensile stress on the concrete exceeds its tensile strength, micro-cracks start to emerge. The steel fiber has a capability of arrest the micro cracks and hence prevent the formation of macro-cracks (Micro-crack arrest mechanism); (2) for further stresses, micro-cracks widen and turn into macro cracks. After macro-crack formation, steel fibers bridge the cracks and prevent further widening of the cracks (Crack bridging mechanism) [4].

\subsubsection{Influence of steel fiber amount}

SFR-SCC properties mainly depend on the steel fiber amount or fractions in the mixture. As the amount of steel fibers increases in the mix, flexural strength, shear strength and flexural toughness values are improved due to the enhancement in the ductility of the mix. In addition, tensile strength and crack opening displacement capacity of the concretes improve with an increasing steel fiber fractions $\left(\mathrm{V}_{\mathrm{f}}\right)$. Inclusion of the high amount steel fibers especially improved the post crack residual tensile strength and ductility of the concretes [5].

Steel fiber content in a mixture generally ranges from 0.3 to $2 \%$. For lower fiber amounts, impact of the fibers on the SCC concrete remains limited. For higher volume fractions than $2 \%$, workability of the SCC reduces and passing ability problems emerge especially in the structures that high percentage structural reinforcement. In addition, steel fibers are expensive materials, usage of higher percentages may become costly. For economic considerations, optimum usage of the steel fibers is considered as $1 \%$ for the majority of structures [6].

\subsubsection{Influence of steel fiber aspect ratio $(l / d)$}

Fiber aspect ratio is the ratio of steel fiber length to diameter. In structural applications, $1 / \mathrm{d}$ ranges from 50 to 100. Large fiber aspect ratio, representing a higher fiber matrix bond area that better bond is available between fiber and matrix and so high energy absorption capacity is obtained in the concretes. The fiber length is also another important factor for structural behavior of the SFR-SCC. Under same fiber aspect ratio, shorter fibers include larger number of fibers than longer fibers; which result in better crack bridging and stress transfer across the cracks [7].

From the light of the literature, two types of steel fibers (hook-end long and straight short), two different fiber volumes $(0.5 \%$ and $1 \%)$ were selected considering economic aspects and different fibrous mixes were produced and mechanically tested to evaluate the mechanical performance of the SFR-SCC specimens.

\section{Materials}

\subsection{SCC Materials and Mix Design}

Ordinary Portland cement (CEM I 42.5R) and fly ash (F-Type) were used as binder materials with densities of 3.14 and $2.13 \mathrm{~kg} / \mathrm{dm} 3$, respectively. A polycarboxylic ether based superplasticizer was used to obtain high flowability. As aggregates, natural sand, crushed sand and coarse aggregate with a maximum grain size (dmax) of $10 \mathrm{~mm}$ were used in the concrete mixture and aggregate densities were $2.60,2.68$ and $2.74 \mathrm{~kg} / \mathrm{dm} 3$, respectively. Two types of steel fibers; hooked-end long fibers with fractions of $0.5 \%$ and $1 \%$, straight short fibers with a fraction of $0.5 \%$ and hybrid fibers (combination of short and long fibers) with a fraction of $1 \%(0.5 \%$ short fiber $+0.5 \%$ long fiber $)$ were used in the study. Straight short fibers have a length of $13 \mathrm{~mm}$ and 
aspect ratio of 81 and hooked-end long fibers have a length of $35 \mathrm{~mm}$ and aspect ratio of 64 . Preliminary experiments were conducted in order to obtain required flowability and stability. After reaching required control mix design with a water-to-cementitious ratio of 0.37 , all other ingredients were kept constant while superplasticizer amount was changed with inclusions of different steel fiber types and fractions in the other mixes. As a total, five different types of selfcompacting concretes including steel hooked-end and straight fibers were produced as control mix, $0.5 \%$ long FRC mix, $1 \%$ long FRC mix, $0.5 \%$ short FRC mix and 1\% hybrid $(0.5 \%$ short $+0.5 \%$ long $)$ FRC mix as can be seen in Table 1 .

Table 1. Mix ingredients and SCC Mixes

\begin{tabular}{|c|c|c|c|c|c|}
\hline \multirow[b]{2}{*}{ Ingredients, $\left(1 \mathrm{~m}^{3}\right)$} & \multicolumn{5}{|c|}{ Batches for SCC (water to binder ratio: 0.37 ) } \\
\hline & $\begin{array}{l}\text { SCC 1 } \\
\text { Control } \\
\text { mix }\end{array}$ & $\begin{array}{c}\text { SCC } 2 \\
0.5 \% \text { Long } \\
\text { FRC Mix }\end{array}$ & $\begin{array}{c}\text { SCC } 3 \\
1 \% \text { Long } \\
\text { FRC Mix } \\
\end{array}$ & $\begin{array}{c}\text { SCC } 4 \\
0.5 \% \text { Short } \\
\text { FRC Mix } \\
\end{array}$ & $\begin{array}{c}\text { SCC } 5 \\
1 \% \text { Hybrid FRC } \\
\text { Mix }\end{array}$ \\
\hline Water $(\mathrm{kg})$ & 220 & 220 & 220 & 220 & 220 \\
\hline Cement (kg) & 420 & 420 & 420 & 420 & 420 \\
\hline Fly Ash (kg) & 180 & 180 & 180 & 180 & 180 \\
\hline Gravel<10 mm (kg) & 636 & 636 & 636 & 636 & 636 \\
\hline Crush Sand (kg) & 353 & 353 & 353 & 353 & 353 \\
\hline Sand (kg) & 424 & 424 & 424 & 424 & 424 \\
\hline Steel Fiber (kg) & 0 & 39 & 78 & 39 & 78 \\
\hline Superplasticizer (kg) & 3.4 & 3.6 & 4.2 & 4.2 & 4.5 \\
\hline
\end{tabular}

Mixing procedure was as follows; in the first stage, cementitious material (cement + fly ash) and aggregates added to the mixer and all dry ingredients without fibers were mixed for 2 minutes. After that water and superplasticizer added to the mixer in 1 minute duration and mixed for 1 more minute. Finally, steel fibers were added (for fiber-reinforced mixes) to the mixer in 1 minute and further mixed for 1 minute for homogeneity. For non-fibrous mixes, dry + wet ingredients were mixed for another 2 minute for equal mixing procedure with mixes including steel fibers. The overall mixing procedure was terminated in 6 minutes. After mixing, fresh state performances of the SCC mixes were evaluated and all of the mixes showed superior flowability characteristics, which was thoroughly investigated in the previous study [8].

\subsection{Casting and Curing of Specimens}

Prepared concrete mixes were cast to the moulds from one end of the specimen and left to flow to the other end. During casting, vibration and/or shaking was not applied to the specimens since concrete was flowing under its self-weight. Concrete surplus was taken by a trowel and surface levelling was applied to all specimens. The specimens were demoulded after 24 hours and kept in a water tank at a temperature of $20 \pm 2{ }^{\circ} \mathrm{C}$ for 28 day curing period time to obtain required strength for tests.

\section{Experimental Program}

\subsection{Compressive Strength Tests}

Force controlled compressive strength tests were carried out on $150 \times 150 \times 150 \mathrm{~mm}$ cube specimens according to TS EN 12390-3 [9] standard at the ages of 1, 7 and 28 days to measure material properties under compression. Specimens were axially loaded at a rate of $13.5 \mathrm{kN} / \mathrm{s}(0.6$ $\mathrm{MPa} / \mathrm{s}$ ), Figure 1. The compressive strength of the cube specimen is calculated by dividing the maximum load reached during the compressive strength test by the crosssectional area of the specimens. For all of the 5 different series, three cube specimens were tested for average values. Specimens were tested under force-controlled test. 
Anıl Niş, Vol.4, No.1, 2018

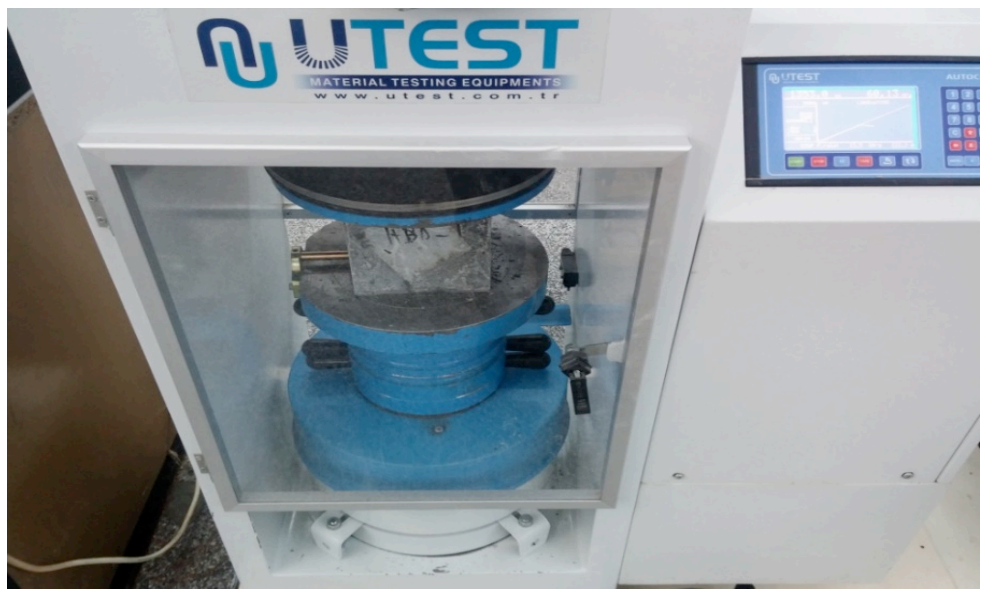

Fig. 1. Compressive strength test

\subsection{Splitting Tensile Strength Test}

Splitting tensile strength tests were carried out on cylinder specimens with a diameter of $100 \mathrm{~mm}$ and a length of $200 \mathrm{~mm}$ at the 28-day in accordance with ASTM C496 /
C496 M-11 standard [10]. Specimens were transversely loaded at a rate of $0.5 \mathrm{kN} / \mathrm{s}(1 \mathrm{MPa} / \mathrm{min})$ as is seen in Figure 2. Three cylinder specimens were cast for all of the 5 series of concretes for splitting tensile strength tests.

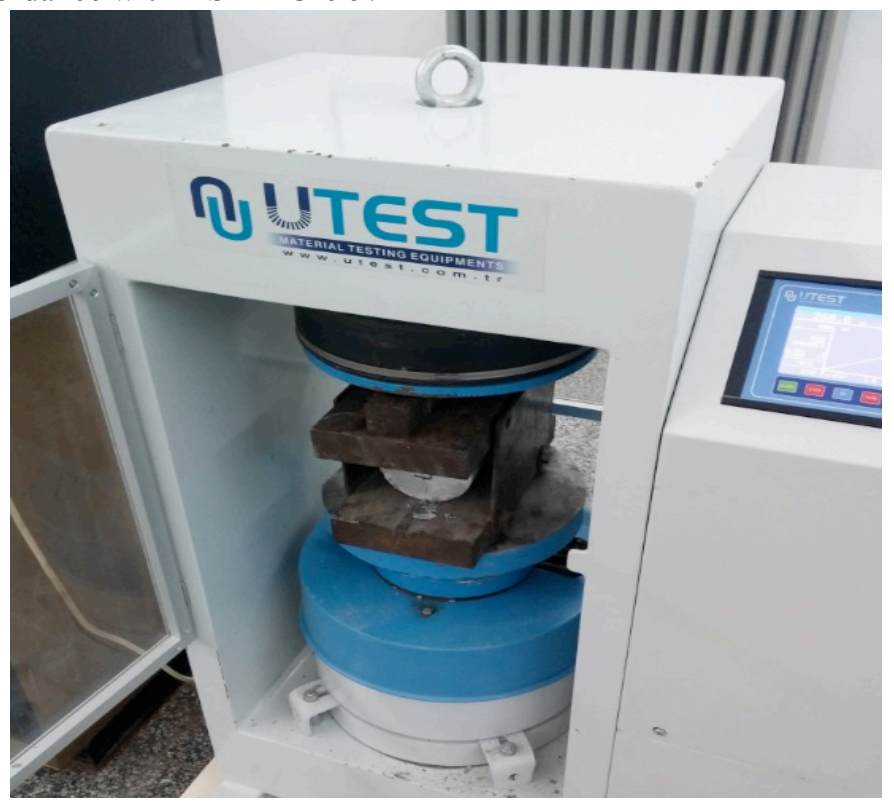

Fig. 2. Splitting tensile strength test

\subsection{Three Point Bending Test on Notched Specimens}

Three-point bending tests were employed on notched specimens to in order to evaluate bending behaviour of different SFR-SCC specimens. Two specimens were poured for each group, and as a total 10 specimens were produced in accordance with EN 14651 standard [11].
All specimens having widths and depths of $150 \mathrm{~mm}$ and lengths of $600 \mathrm{~mm}$ and notches were composed on the bottom of the specimens with a $4 \mathrm{~mm}$ width and $25 \mathrm{~mm}$ height as is seen in Figure 3. Specimens had a $125 \mathrm{~mm}$ effective height after notch and were tested under three point bending using MTS testing machine. 


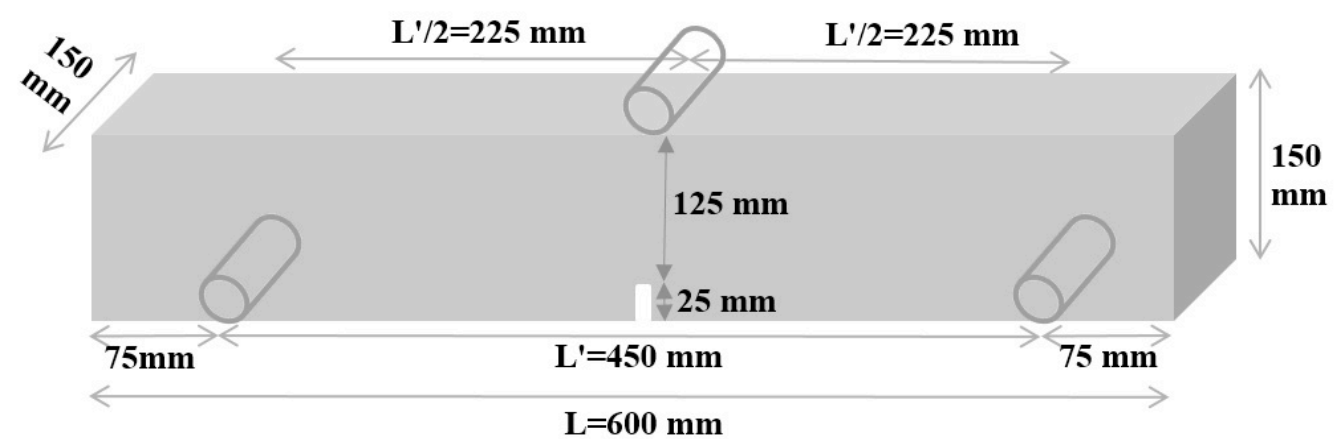

Fig. 3. Three point loading scheme

Based on the standard, three point flexural loading was applied in crack mouth opening displacement (CMOD) control at two different rates; CMOD rate was of 0.05 $\mathrm{mm} / \mathrm{min}$ from zero to $0.1 \mathrm{~mm} \mathrm{CMOD}$, and was increased to $0.2 \mathrm{~mm} / \mathrm{min}$ from $0.1 \mathrm{~mm}$ CMOD to $4 \mathrm{~mm}$ CMOD, Figure 4.
Experimental procedure was terminated when a CMOD value of $4 \mathrm{~mm}$ was reached. As a result of the tests, force versus CMOD curves of the SCC specimens was obtained and results were evaluated accordingly.

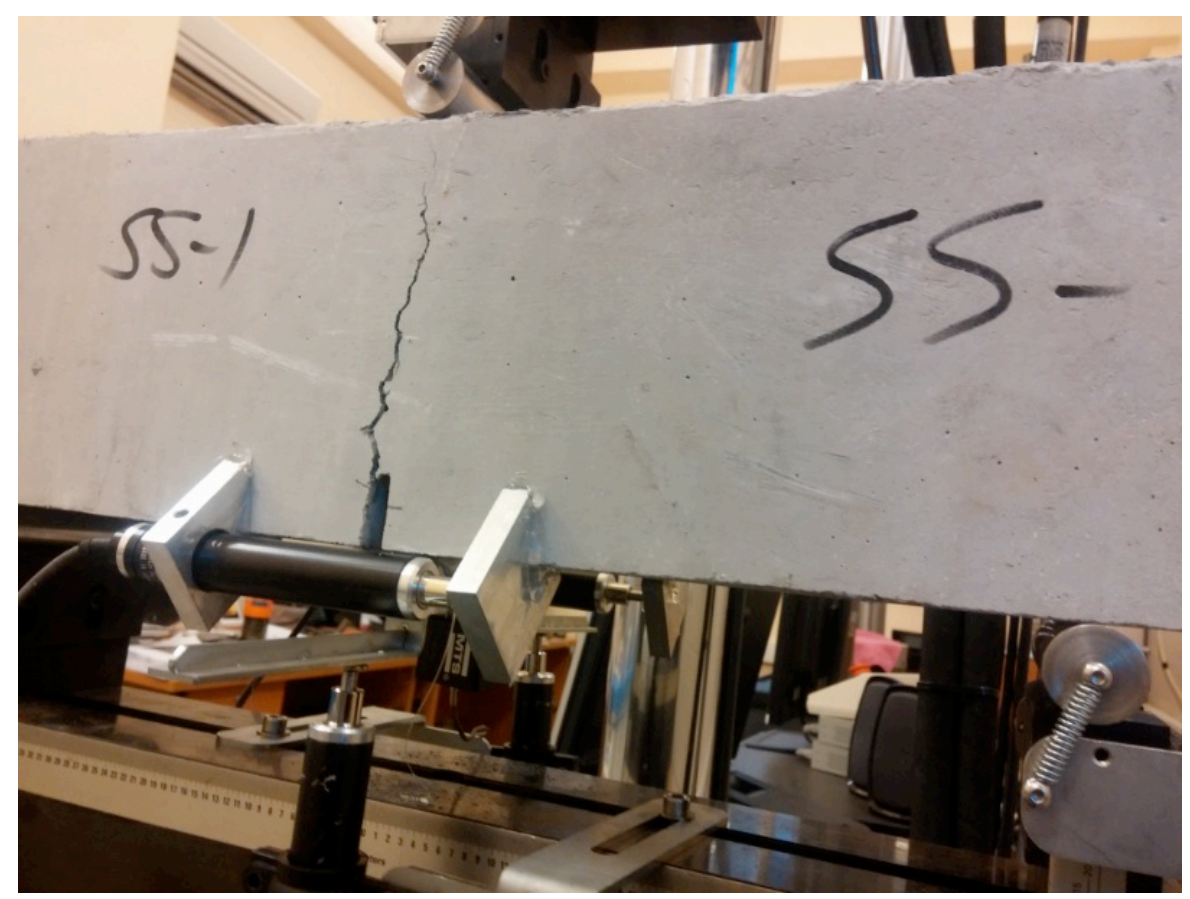

Fig. 4. CMOD controlled flexural loading

\section{Results and Discussions}

\subsection{Compressive Strength Test Results}

Compressive strength test results of the cube SCC specimens were determined at the ages of 1,7 and 28 days as is given in Table 2. Results indicated the average of the three specimens for each mix. Compressive strength values ranged from $19 \mathrm{MPa}$ to $24.5 \mathrm{MPa}, 44.5 \mathrm{MPa}$ to $50 \mathrm{MPa}$ and 57.5 $\mathrm{MPa}$ to $62 \mathrm{MPa}$ at the ages of 1,7 , and 28 days, respectively. Increase in compressive strength values was found when fibers were added. The extent of increase was around 2-3\% when $0.5 \%$ short and long fibers were added, while 6-7\% increase was observed for $1.0 \%$ long and hybrid fiber added specimens.

\subsection{Splitting Tensile Strength Results}

Splitting tensile strength results showed that steel fibers have a significant influence on splitting tensile strength of concrete especially for high steel fiber fractions $(\geq 1 \%)$. For $0.5 \%$ long and short fiber reinforced SCC specimens, splitting tensile strengths increased up to $5 \%$ and $13 \%$, respectively, whereas for $1 \%$ long and hybrid fiber reinforced SCC specimens, splitting tensile strength increased up to $83 \%$ and $55 \%$, respectively as is seen in Table 3. 
Table 2. Compressive strength values of concretes

\begin{tabular}{|c|c|c|c|}
\hline \multirow{2}{*}{ SCC specimens } & \multicolumn{3}{|c|}{ Compressive Strength (MPa) } \\
\cline { 2 - 4 } & $1^{\text {st }}$ day & $7^{\text {th }}$ day & $28^{\text {th }}$ day \\
\hline Control (Non-Fibrous) & 20.72 & 44.47 & 57.75 \\
\hline $0,5 \%$ Long FRC & 19.01 & 48.06 & 59.23 \\
\hline $0,5 \%$ Short FRC & 20.44 & 47.79 & 58.92 \\
\hline $1 \%$ Long FRC & 23.46 & 47.53 & 61.98 \\
\hline $\begin{array}{l}1 \% \text { Hybrid FRC } \\
(0,5 \% \text { S }+0,5 \% \mathrm{~L})\end{array}$ & 24.53 & 50.05 & 61.18 \\
\hline
\end{tabular}

\subsection{Three Point Bending Test Results}

Three-point bending tests results on notched specimens indicated that SFR-SCC specimens showed higher load bearing and displacement capacity when compared to plain concretes as can be seen in Figures 5 to 8. The reason of the sharp decrease in the load was resulted from the CMOD controlled loading. In Figures 5 and 6, maximum flexural load was around $20 \mathrm{kN}$ for control specimens; whereas maximum flexural load ranged from $23 \mathrm{kN}$ to 32 $\mathrm{kN}, 26 \mathrm{kN}$ to $33 \mathrm{kN}$ for $0.5 \%$ long and short FRC specimens, respectively. In Figures 7 and 8, maximum flexural load ranged from $44 \mathrm{kN}$ to $48 \mathrm{kN}, 45 \mathrm{kN}$ to $47 \mathrm{kN}$ for $1 \%$ long and hybrid FRC specimens. Area under the load - CMOD curve (toughness) was highest for $1 \%$ fiber reinforced mixes and lowest for the control specimens.

Table 3. Splitting tensile strength results of concretes

\begin{tabular}{|c|c|}
\hline Specimens & $\begin{array}{r}\text { Splitting Tensile Strength } \\
(28 \text { day })(\mathrm{MPa})\end{array}$ \\
\hline Control (Non-fibrous) & 4.14 \\
\hline $0.5 \%$ Long FRC & 4.35 \\
\hline $0.5 \%$ Short FRC & 4.67 \\
\hline $1 \%$ Long FRC & 7.57 \\
\hline $\begin{array}{c}1 \% \text { Hybrid FRC } \\
(0.5 \% \mathrm{~S}+0.5 \% \mathrm{~L})\end{array}$ & 6.39 \\
\hline
\end{tabular}

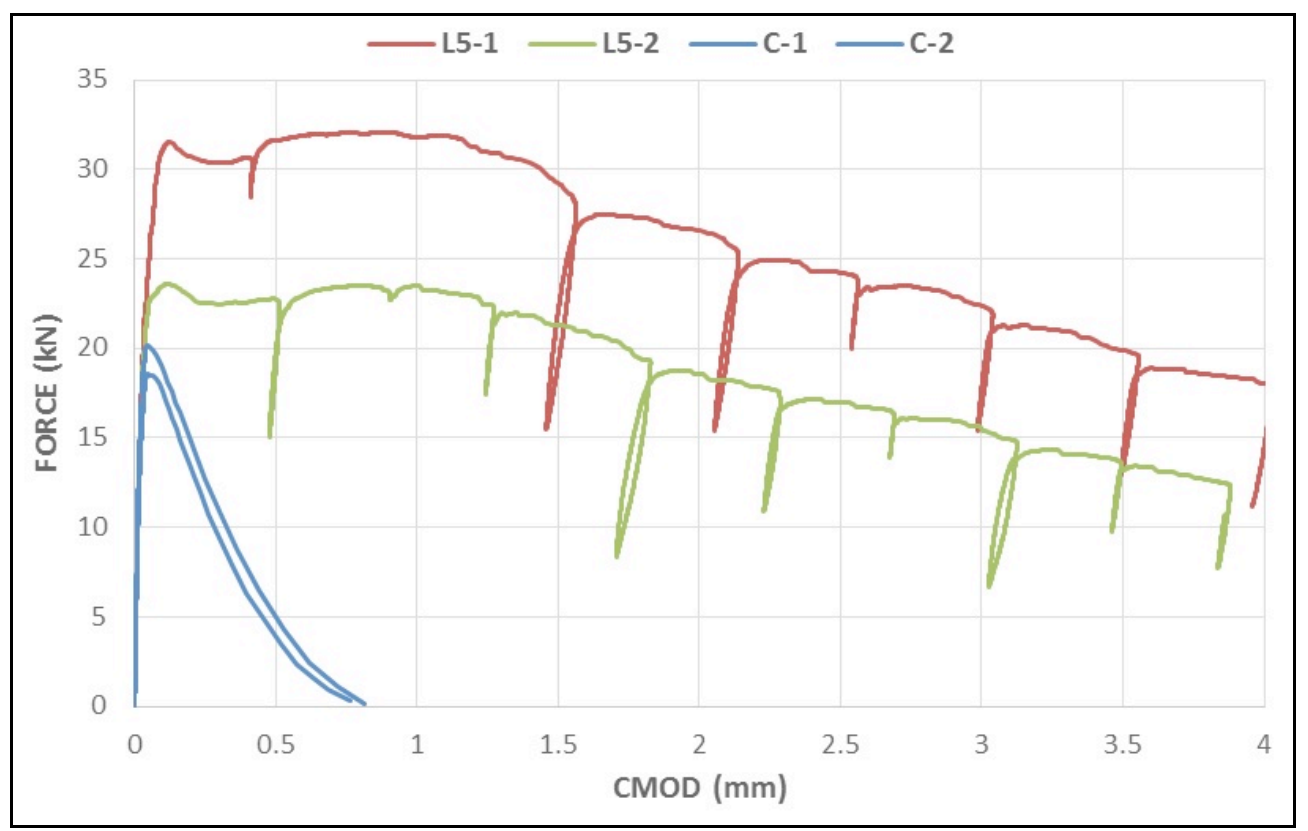

Fig. 5. Experimental results of $0.5 \%$ long FRC specimens (L5) and control (C) specimen 
INTERNATIONAL JOURNAL Of ENGINEERING TECHNOLOGIES-IJET

Anıl Niş, Vol.4, No.1, 2018

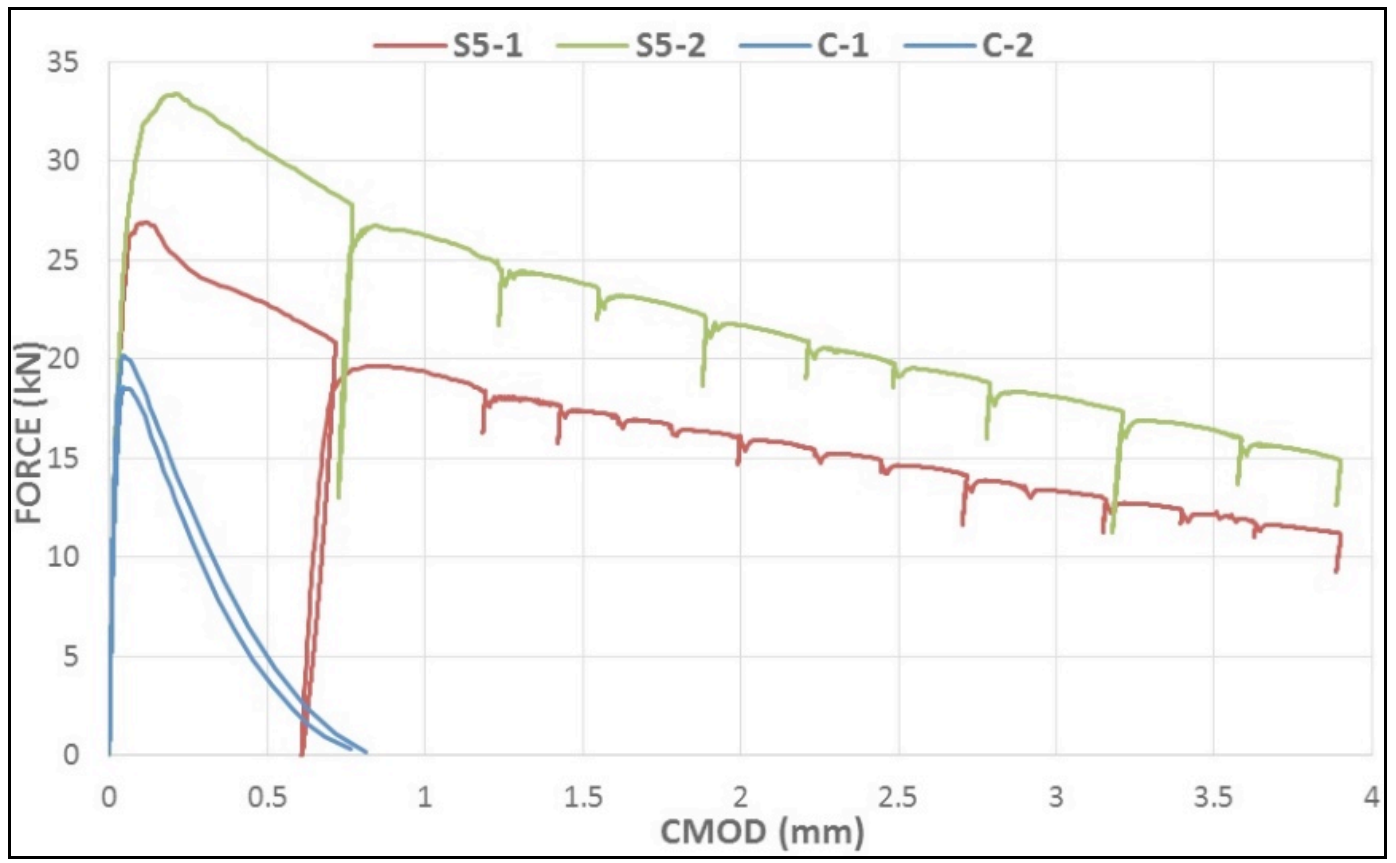

Fig. 6. Experimental results of $0.5 \%$ short FRC specimens (S5) and control (C) specimens

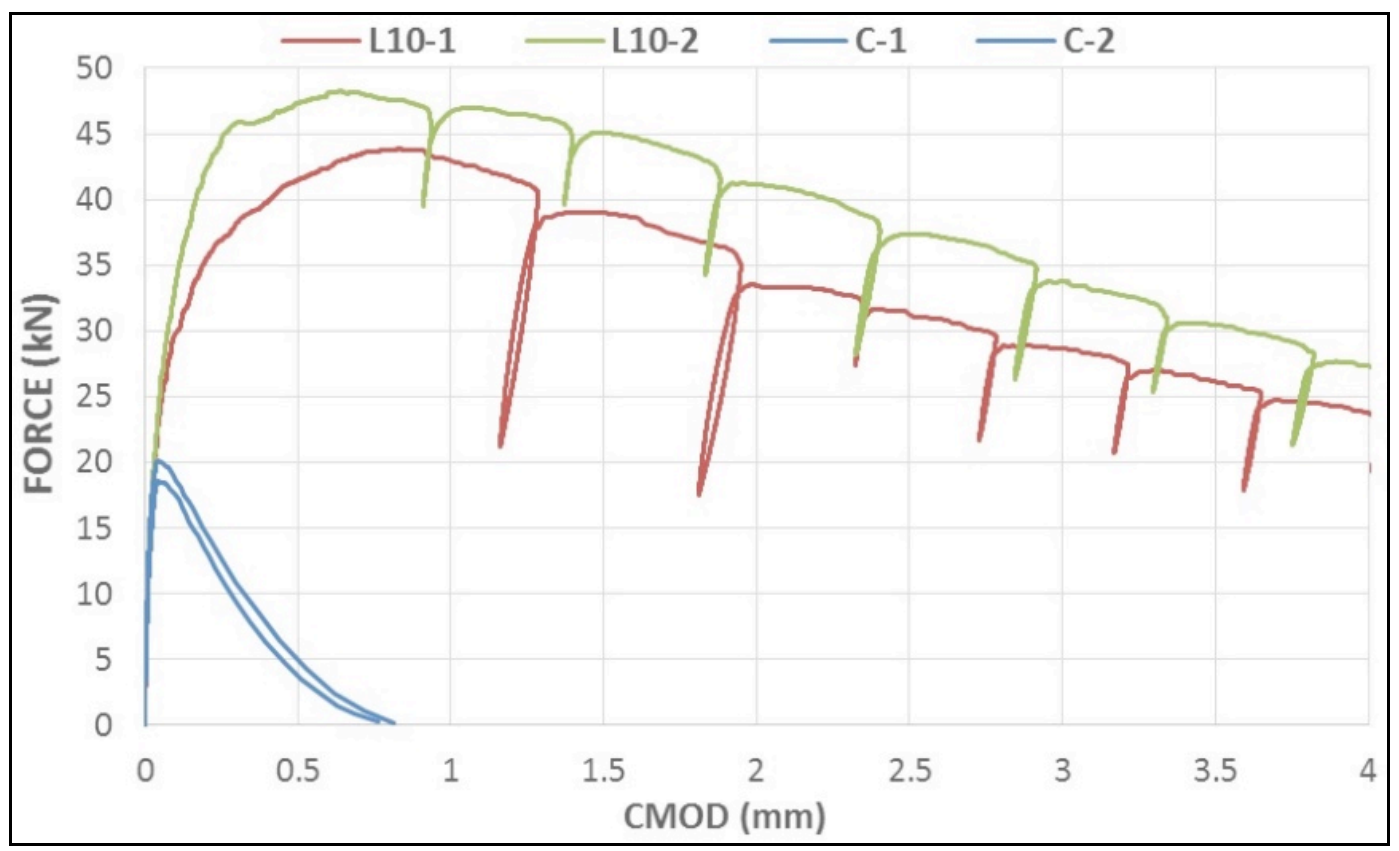

Fig. 7. Experimental results of 1\% long FRC specimens (L10) and control (C) specimens 


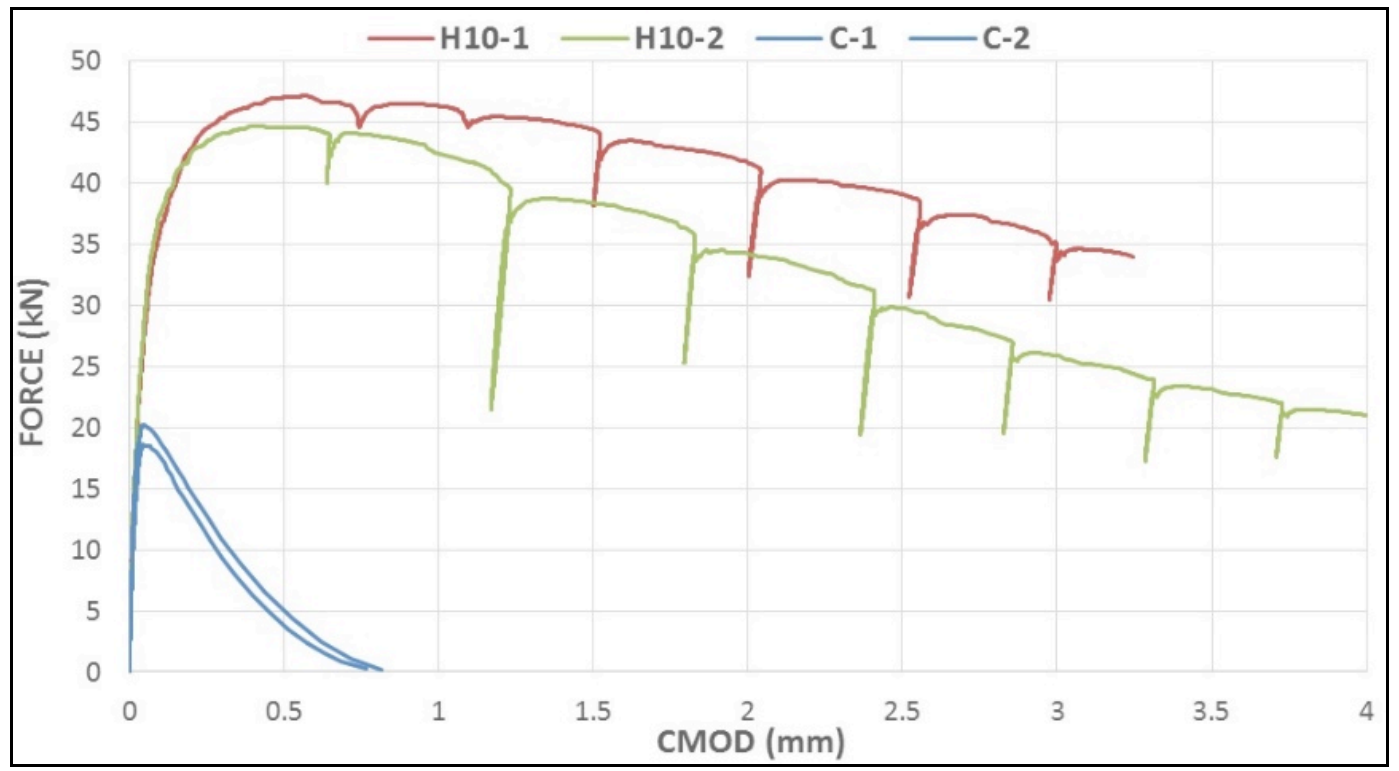

Fig. 8. Experimental results of $1 \%$ hybrid FRC specimens (H10) and control (C) specimens

\section{Conclusion}

Compressive strength, splitting tensile strength and 3-point notched bending tests were carried out on different SFR-SCC specimens and following conclusions were drawn:

Steel fiber addition to the SCC mixes slightly increased the compressive strength compared to plain mix. The extent of the increase was higher for $1 \%$ fiber - reinforced mixes.

Steel fibers were found to have a significant influence on splitting tensile strength of concrete, especially for high steel fiber fractions $(\geq 1 \%)$. Low amount of steel fibers $(0.5 \%)$ had no or little contribution to splitting tensile strength results.

Maximum flexural load increased with an increase in steel fiber volumes of SCC specimens. Long and hybrid fibrous specimens with a fiber volume of $1 \%$ were found to show the best performance by means of flexural strength and toughness. However, lower amounts of steel fiber addition into SCC improved ductility of SCC specimens significantly as compared to plain SCC specimens. It can be also concluded that steel fiber volume improved flexural strength and toughness more than steel fiber type and aspect ratio.

\section{References}

[1] Aoude H., "Structural behaviour of steel fiber reinforced concrete beams', $\mathrm{PhD}$ Thesis, McGill University, Montreal, Quebec, Canada, 2007.

[2] Cunha V. M. C. F., "Steel Fibre Reinforced SelfCompacting Concrete', PhD Thesis, University of Minho, Braga, Portugal, 2010.

[3] Löfgren I., "Fibre Reinforced Concrete for Industrial Construction', $\mathrm{PhD}$ Thesis, Chalmers University of Technology, Gothenburg, Sweden, 2005.
[4] Mpegetis S. O., "Behavior and Design of Steel Fiber Reinforced Concrete Slabs", $\mathrm{PhD}$ Thesis, Imperial College London, London, United Kingdom, 2012.

[5] Kooiman A.G., "Modelling Steel Fibre Reinforced Concrete for Structural Design', PhD Thesis, Delft University of Technology, Delft, Netherlands, 2000.

[6] Prisco M.D., Felicetti R., Iorio F. and Gettu R., “'On the Identification of SFRC Tensile Constitutive Behaviour', Fracture Mechanics of Concrete Structures, Vol.2, No.1, pp.541-548, 2001.

[7] Luo J.W., "Behavior and Analysis of Steel Fibre Reinforced Concrete under Reversed Cyclic Loading', PhD Thesis, University of Toronto, Toronto, Ontario, Canada, 2014.

[8] Niş A., Özyurt N., and Özturan T., "Fresh State Properties of Steel Fiber Reinforced Self-Compacting Concretes with Various Fiber Volumes', ACE Conference, 2016.

[9] TS EN 12390-3, “"Testing Hardened Concrete - Part 3: Compressive Strength of Test Specimens”, 2003.

[10] ASTM C496/C496 M-11, “Standard Test Method for Splitting Tensile Strength of Cylindrical Concrete Specimens", 2011.

[11] EN 14651, “Test Method for Metallic Fibered Concrete - Measuring the Flexural Tensile Strength (Limit of Proportionality (LOP), Residual)', European Standard, 2005 . 